\title{
Discursos dos psicólogos no contexto da comissão de orientação e ética
}

\section{Psychologists's speech within the context of orientation and ethics comission}

\section{Discursos de psicólogos en el contexto de la orientación y la ética}

\section{Lygia Santa Maria Ayres*}

Universidade Federal Fluminense - UFF, Niterói, Rio de Janeiro, Brasil

\section{Cíntia de Sousa Carvalho**}

Centro Universitário de Barra Mansa - UBM, Barra Mansa, Rio de Janeiro, Brasil

\author{
Mariana Chaves Botelho Barreira*** \\ Consultório Particular - Rio de Janeiro, Rio de Janeiro, Brasil
}

\begin{abstract}
RESUMO
Buscamos, neste artigo, analisar os discursos escritos, e encaminhados por psicólogos, denunciados à Comissão de Orientação e Ética em denúncias e/ou processos éticos, tramitados no Conselho Regional de Psicologia do Rio de Janeiro. Nosso objetivo, ao problematizar práticas/discursos veiculados pelos psicólogos denunciados em seu conselho de classe, consiste em colocar em análise alguns argumentos, lógicas e premissas que atravessam os discursos desses profissionais num momento em que sua atuação/intervenção é questionada. Pautadas nas contribuições de Foucault, Bakhtin, Guattari e outros teóricos, as autoras em suas indagações transpõem o universo do psicólogo denunciado levantando discursos/práticas para além dos argumentos desses profissionais, colocando em cena a própria constituição da comissão de orientação e ética. Esse trabalho, de modo algum, pretende expor, rechaçar ou mesmo intimidar colegas de profissão, mas contribuir por meio de reflexões para a construção de uma psicologia mais comprometida com a população, ao tentar desconstruir conceitos e pilares que ainda sustentam uma psicologia dita neutra, objetiva e científica e, por efeito, psicólogos descontextualizados.
\end{abstract}

Palavras-chaves: ética, práticas, discursos, psicólogos.

\begin{abstract}
This article aims to analyse the speeches written and submitted by psychologists to the Regional Psychology Council of the State of Rio de Janeiro in relation to allegations and/or law suits forwarded through legal channels by the Regional Psychology Council of the State of Rio de Janeiro. Our goal is to bring into light problematic practices/speeches used by the psychologists denounced by their class councils consists of analyzing some
\end{abstract}


arguments, logics and premises contained in the speech of such professionals in a moment where their actions/interventions are being questioned. Based on the contributions by Foulcault, Bakhtin, Guattari and others, the authors in their enquiries transpose the denounced psychologist's universe by raising speeches/practices to a point beyond these professionals' arguments, placing them in the realm of the contitution of the orientation and ethics comission. This work does not intend to expose, defy or intimidate colleagues in any way, but to contribute through considerations to the formation of psychology as a field concerned with the population by bringing down concepts and foundations that still sustain psychology said to be neutral, objective and scientific and as a result, such professionals.

Keywords: ethic, practices, psychologists, speech.

\section{RESUMEN}

En este artículo analizamos los discursos escritos y transmitidos por los psicólogos denunciados a la Comisión de Orientación y Ética en los informes o procesos éticos que tramitan en el Consejo Regional de Psicología de Río de Janeiro. Nuestra meta, al problematizar prácticas y discursos presentados por psicólogos denunciados en el colegio de su asociación, consiste en analizar algunos argumentos, razonamientos y suposiciones que se muestran a través de los discursos de estos profesionales en un momento en que se cuestiona su acción e intervención. Basadas en las aportaciones de Foucault, Bakhtin, Guattari y otros teóricos, las autoras en sus indagaciones transponen el universo del psicólogo denunciado y enseñan discursos y prácticas más allá de los argumentos de estos profesionales, lo que pone en tela de juicio la propia constitución de la Comisión de Orientación y Ética. Este trabajo no pretende de manera alguna exponer, defender o incluso intimidar a colegas de profesión, sino contribuir a través de reflexiones a la institución de una psicología más comprometida con la población, mientras que intenta deshacer conceptos y pilares que aún mantienen una psicología dicha neutral, objetiva y científica y, por consiguiente, psicólogos alejados del contexto profesional.

Palabras clave: ética, prácticas, discursos, psicólogos.

\section{Constituindo-nos Psicólogos... nosso universo de análises}

Em 1962, pela Lei 4.119 criou-se e regulamentou-se a profissão PSICÓLOGO com a função de adequar, ajustar e adaptar o indivíduo ao mundo moderno, apesar de seu discurso psi já se encontrar disseminado em práticas cotidianas na escola, no hospital e até mesmo no judiciário. Em 20 de dezembro de 1971, pela Lei 5.766, com intuito de orientar, fiscalizar e disciplinar, bem como zelar pela fiel observância dos princípios éticos e contribuir para o desenvolvimento da psicologia como ciência e profissão, foram criados o Conselho Federal de Psicologia e 07 (sete) Conselhos Regionais. Dos 07 (sete) Regionais iniciais, hoje contamos com 23 Conselhos Regionais.

Dentre as inúmeras comissões de trabalho que os compõem, a Comissão de Orientação e Ética (COE) nos interessa particularmente. Essa é uma comissão permanente no Sistema de Conselhos de 
Psicologia que tem como finalidade receber denúncias contra psicólogos em seu exercício profissional, avaliar essas denúncias e instruir processos éticos. Para tal, esta comissão pauta-se em documentos oficiais e jurídicos como o Código de Ética do Profissional Psicólogo (CEPP), datado de 2005, o Código de Processamento Disciplinar (CPD), elaborado em 2007, bem como posicionamentos teórico-práticos da psicologia como um campo de intervenção éticopolítico.

No Conselho Regional do Rio de Janeiro, as denúncias são avaliadas por uma comissão de instrução formada por um psicólogo conselheiro da gestão em vigor e dois psicólogos colaboradores previamente legitimados em Assembleia ordinária de conselheiros. A instrução é iniciada pela distribuição da representação a uma das comissões de instrução. Dessa representação consta a denúncia construída pelo(s) denunciante(s) (devidamente protocolada e recebida na COE), além dos esclarecimentos elaborados pelo(s) psicólogo(s) denunciado(s).

Após leitura e análise, essa comissão produz um Parecer de Representação, que é encaminhado e apreciado pelo Plenário do Conselho Regional, sendo aprovado ou recusado pelo grupo de conselheiros. Esse documento pode sugerir o arquivamento da representação ou a abertura de processo ético. A decisão tomada pelo Plenário é informada às partes, denunciante(s) e psicólogo(s) denunciado(s), que têm a oportunidade de pedir reconsideração da resolução, caso discordem dessa. Havendo pedido de reconsideração de alguma das partes, a comissão de instrução solicita à outra parte que encaminhe um documento contendo contra-razões às alegações apresentadas na reconsideração. Esses novos documentos são analisados pela comissão de instrução, que elabora Parecer de Reconsideração a partir de uma segunda discussão. O documento pode sugerir a manutenção da decisão votada anteriormente pelo Plenário ou alterações na mesma. Essas mudanças podem fazer referência à retirada de algum artigo do CEPP, que tenha sido indicado como infração no Parecer de Representação, ou até mesmo a alteração da indicação de arquivamento ou abertura de processo. 0 Parecer de Reconsideração é encaminhado e apreciado pelo Plenário do Regional. Sendo a decisão dos conselheiros pelo arquivamento da representação, essa é arquivada pela COE. Caso a indicação seja de abertura de processo ético, inicia-se a fase de instrução de processo.

Na instrução processual, ao(s) psicólogo(s) denunciado(s) é solicitado o encaminhamento de sua defesa escrita à COE e as partes têm a oportunidade de apresentar, caso haja, nova(s) prova(s) e/ou testemunha(s). Havendo a indicação de testemunha(s), a comissão de instrução promove uma oitiva de testemunha(s) com a participação facultativa das partes. Em seguida, denunciante(s) e psicólogo(s) denunciado(s) são intimados a apresentar suas alegações finais. Ao final desses procedimentos, a Comissão de Ética 
encaminha o processo para um conselheiro relator, membro integrante do Regional, mas não da COE. O relator analisa todo o processo e elabora um parecer que será apreciado pelo Plenário. Nesse documento, ele sugere absolvição do(s) psicólogo(s) denunciado(s) ou a aplicação de uma das penalidades constantes do CEPP. A decisão final caberá aos conselheiros e será tomada através de um procedimento de votação.

Neste artigo buscamos analisar, tendo em vista o cenário acima apresentado, os discursos escritos e encaminhados por psicólogos denunciados à Comissão de Orientação e Ética em denúncias e/ou processos éticos tramitados no Conselho Regional de Psicologia do Rio de Janeiro. Nosso objetivo, ao problematizar práticas/discursos veiculados pelos psicólogos denunciados em seu conselho de classe, consiste em colocar em análise alguns argumentos, lógicas e premissas que atravessam os discursos desses profissionais num momento em que sua atuação/intervenção é questionada. Esse trabalho, de modo algum, pretende expor, rechaçar ou mesmo intimidar colegas de profissão, mas contribuir por meio de reflexões para a construção de uma psicologia mais comprometida com a população, ao tentar desconstruir conceitos e pilares que ainda sustentam uma psicologia dita neutra, objetiva e científica e, por efeito, psicólogos descontextualizados.

\section{0 discurso argumentativo}

Pensar em argumentação nos permite uma viagem ao passado, uma associação quase que direta com a Grécia antiga e, mais especificamente, ao estudo da Retórica. Aristóteles em Arte Retórica procurou estudar a estrutura e o funcionamento do discurso, e suas ideias tornaram-se um manual para a construção de um texto persuasivo. A Retórica, segundo ele, é um meio para a argumentação a fim de fazer um auditório repleto admitir as ideias propostas.

Essa arte, a Retórica, foi perdendo força ao longo dos anos sendo, inclusive, rechaçada no Romantismo e, em meados do século $X X$ ressurgiu ganhando expressividade. Desde então, inúmeros são os autores que vêm se dedicando ao estudo da argumentação.

Para Anscombre e Ducrot (1988), o uso da linguagem é essencialmente argumentativo, ou seja, orienta os enunciados no sentido de determinadas conclusões. Na mesma direção, Bakhtin (1986) postula que a palavra é um ato de duas faces, determinado tanto por quem o emite, como por quem o recebe. Assim, a medida mínima da linguagem é o diálogo e não um enunciado monológico. 0 diálogo é constituído de linguagem e vale lembrar que esse, o diálogo, não é necessariamente uma conversa entre duas pessoas, pois quando se escreve, se tem presente o Outro e é, por ele 
constituído. Em outras palavras, o ouvinte hipotético do discurso estará sempre presente, pelo simples fato de habitar a construção do enunciado enquanto potência de escuta e interpretação, constrangendo o discurso pois: "A resposta presumida do outro atua no meu enunciado." (Amorim, 2001, p. 122). Enfim, o discurso possui projeção e memória, elementos que são produzidos, enredados pelo olhar do Outro, Outro este que necessariamente atravessa meu ato de fala. São essas reflexões que induzem Bakhtin a compreender que a linguagem não é um instrumento que veicula e traduz ideias, mas é vista como uma prática social.

Nesse sentido, a argumentação age sobre os indivíduos, sobre sua opinião e não sobre o conceito de verdade. Seu objetivo é a procura de adesão do destinatário e deverá considerar sempre as diferenças individuais. Em outras palavras, a argumentação não visa afirmar se uma determinada tese é falsa ou verdadeira, mas procura influenciar/persuadir o outro. Ela terá atingido seu propósito não quando chegar à verdade, mas quando tiver convencido seu destinatário.

Charaudeau (1996) amplia a discussão do ato de linguagem introduzindo o seu caráter semiolinguístico. Ou seja, para o autor, este ato não se resume apenas a um ato de comunicação, de consequência única de uma produção de uma mensagem por um emissor para um receptor, mas sim o resultado de duas atividades dialéticas: a de produção e a de interpretação, que dependem de saberes supostos que circulam entre os sujeitos de linguagem. Acrescenta ainda o autor, que o ato de linguagem é pautado em estratégias discursivas, dentre elas postula que o sujeito comunicante concebe, organiza e representa suas intenções para produzir certos efeitos de conviç̧ão ou de sedução sobre o sujeito interpretante, para levá-lo a se identificar ao sujeito destinatário ideal, isto é, a imagem construída pelo sujeito identificante do sujeito interpretante. No nosso estudo, podemos hipotetizar que o sujeito comunicante, o psicólogo denunciado, constrói discursos visando seduzir ou convencer o sujeito interpretante, psicólogos integrantes da Comissão de Instrução que apreciam o caso, a partir da imagem que esse profissional faz dos colegas da comissão.

Charaudeau continua seus trabalhos chamando-nos a atenção para três modos de Organização Enunciativa que tem por função estabelecer relações de influência entre os sujeitos comunicante e interpretante, são eles: o alocutivo, o elocutivo e o delocutivo. Entende-se por alocutivo, o discurso cujas formas linguísticas mais relevantes são as do sujeito destinatário a quem se deseja provocar. Visualiza-se o elocutivo quando as formas linguísticas que se destacam são as que marcam o sujeito comunicante, que se posiciona. Por último, evidencia-se o delocutivo quando o sujeito 
comunicante fica ausente e também não há marcas linguísticas do destinatário. Nesse modo, o que sobressai é o discurso.

Vejamos agora de que modo as contribuições de Foucault nos ajudam a compreender as relações entre linguagem/discurso e psicologia, analisando conceitos importantes para o objetivo maior deste texto, a saber: verdade e normalidade.

\section{Os discursos especialistas em Foucault}

Foucault, em seus estudos sobre a relação entre saber, poder e verdade na modernidade, afirma que são múltiplas as correlações de forças, de lutas e de embates que organizam estados de poder. Segundo o autor, a verdade só pode ser compreendida no contexto das relações de força.

Essas produções de verdade não podem ser dissociadas do poder e dos mecanismos de poder, ao mesmo tempo que esses mecanismos de poder tornam possíveis, induzem essas produções de e, porque essas produções, têm, elas próprias, efeitos de poder que nos unem, nos atam (Foucault, 2006, p.229).

Nossa vontade de verdade, como nomeia Foucault, é um dos procedimentos de controle do discurso. A ruptura entre o falso e o verdadeiro deslocou-se, ao longo do tempo, do ato do dizer para o dito. A verdade, que anteriormente era afirmada por quem estava no lugar do verdadeiro como os oráculos e os filósofos, hoje, passou a ser qualidade não mais relacionada ao lugar de enunciação, mas ligada ao enunciado. Ou seja, para o autor essa legitimidade organiza-se por meio de um conjunto de práticas sociais, são elas que engendram os saberes, que materializam os enfrentamentos das relações de poder e que constituem subjetividades.

As práticas sociais se concretizam pela ação daqueles que as constituem, as produzem e reproduzem pelos discursos. Discurso não como linguagem ou representação, não como palavras que nomeiam e classificam objetos, mas a prática discursiva como instituinte dos objetos.

Discurso é prática, é produção, a possibilidade de fala inscrita em condições historicamente determinadas. No ato da fala, oral ou escrita, reeditam-se verdades e produzem-se brechas e rupturas bem como se exercitam os enfrentamentos dos jogos de poder. Assim sendo, discurso é ato.

Ainda para Foucault (2006), a questão da verdade deve ser repensada em termos de regime de verdade, ou seja, devemos compreender quais são as condições de possibilidade que determinam 
que alguns processos, em detrimento de outros, sejam considerados verdadeiros ou falsos. O autor considera que cada sociedade estipula para si regimes de verdades que serão ou não acolhidos e que, tais escolhas, não são neutras, pois atravessadas por interesses econômicos, políticos, etc. Vivemos, então, um jogo incessante de lutas ideológicas que buscam estabilizar alguns pressupostos de modo a fazê-los serem considerados fidedignos. Nesta seara, o discurso científico no Ocidente possui um grande peso e nele incluímos os discursos enunciados pela ciência psicológica.

A psicologia possui um regime de verdade relativamente aceitável, que atua pela via das práticas de enunciação do eu ou práticas confessionais. Ao se tornar ciência, a psicologia atua como um dispositivo, ou seja, um conjunto não simétrico de linhas de força que congregam poder-saber-subjetivação. É assim que esta ciência atua com uma máquina produtiva que se estabelece ao fazer-ver, fazerfalar, fazer-fazer. Vejamos, a seguir, a história da construção deste saber psicológico, de modo que possamos compreender como os pressupostos dessa ciência específica atuam nas práticas discursivas contemporâneas.

A preocupação moderna com o homem, visto como lócus do saber e da verdade, abriu espaço para a constituição de diversas reflexões científicas dedicadas a compreender os seres humanos e suas práticas. Dentre eles, surge a psicologia enquanto uma ciência humana disposta a esclarecer o funcionamento da mente. Para se estabelecer enquanto ciência válida frente a um objeto de pesquisa cambiante e errante teve de se filiar à lógica das ciências naturais, que neste momento já eram consolidadas no campo epistemológico. A psicologia foi herdeira então do pressuposto de que: “... o caminho de todo conhecimento científico deve passar pela determinação de relações quantitativas, pela construção de hipóteses e pela verificação experimental." (Foucault, 2011, p. 133).

A ciência psicológica, para ratificar as exigências naturalistas, buscou no homem aquilo que respondesse às indagações quantitativas e empíricas, tendo como ferramenta central o comportamento humano. Ao se firmar apenas neste solo naturalista, acabou negando o próprio homem em sua humanidade, reduzindo-o àquilo que pudesse ser visto e medido. Posteriormente, na tentativa de avançar em seus pressupostos e responder novas questões que acabaram lhe sendo impostas, a psicologia ampliou seu espectro de ação. Agora, não apenas o comportamento humano, mas as práticas humanas passaram a ser foco deste campo de saber. Entretanto, sendo a psicologia uma ciência que se afilia a um projeto de ajustamento social, as práticas foram vistas do ponto de vista do fracasso e da contradição, daquilo que deve ser adequado. Normalizar passa a ser o projeto. Assim, mais uma vez se aproxima dos pressupostos naturalistas: 
Inversamente, a psicologia se colocou como questão os problemas suscitados por essas práticas: problema do sucesso e do fracasso escolar, problema da inserção do doente na sociedade, problema da adaptação do homem à sua profissão... Sem forçar uma exatidão, pode-se dizer que psicologia contemporânea é, em sua origem, uma análise do anormal, do patológico, do conflituoso, uma reflexão sobre as contradições do homem consigo mesmo (Foucault, 2011, p. 134-135).

O binômio normal x patológico esteve desde sempre na trajetória percorrida pela psicologia, quando esta junto à Psiquiatria, ocuparamse da loucura. O louco, ao se tornar responsabilidade das cidades, passa a habitar o regime do internamento. Assim, a lógica asilar faz com que o âmbito médico se ocupe desses sujeitos que incomodavam a ordem da razão e da moral. Nesse quadro, psiquiatria e psicologia passam a ser discursos que surgem para operar categorias como normal e patológico. As figuras do louco, do anormal, do doente, servem menos para afirmar aquilo que é abjeto à norma, mas se destinam a dar contorno ao que é normal, esperado e aceitável. Reiteram e afirmam um ideal de normalidade, de sujeitos legítimos que, portanto, detém a verdade sobre si e sobre os outros. (Foucault, 2000).

\section{Nosso percurso e nossas ferramentas}

Caminhamos pelo viés qualitativo por entender que os objetos a serem analisados, no nosso caso, as redes que tecem os discursos veiculados pelos psicólogos denunciados em seu Conselho de Classe, não possuem uma essência, uma natureza ser descoberta ou revelada, mas constituem-se e afirmam-se enquanto produções sócio históricas.

Nosso norte foi orientado pela trajetória entendida por Foucault como analítica interpretativa, que tem como proposta, partindo de um "diagnóstico" da situação atual, escrever a história do presente. A dimensão dita analítica busca, no passado, problemas e ferramentas conceituais, e não soluções e conclusões neles baseadas. O suporte interpretativo funda-se na ideia de que a história de uma sociedade só pode ser entendida e lida em termos de suas práticas cotidianas.

Do ponto de vista das etapas do processo metodológico, há que explicitarmos que as autoras deste texto fizeram parte de uma das comissões de trabalho que se dedicava a estudar e analisar as representações que chegavam até o Conselho Regional de Psicologia. Assim, muitas das reflexões que moveram o desejo de construir este texto, vieram de questionamentos surgidos ao longo desta atividade. 
Mais do que pensar no trabalho das Comissões de Instrução, nosso interesse maior com este texto é compreender o que a experiência vivenciada neste espaço apresenta de fértil para a construção de indagações que questionam a psicologia e seu fazer.

Para a realização deste texto, com a concordância dos conselheiros do XII e XIII plenários e dos presidentes da Comissão de Ética às épocas (2007/2010 e 2010/2013), foram analisadas algumas representações que tramitaram no CRP. Em nenhum momento faremos referência a discursos argumentativos dos profissionais representados, na medida em que nosso propósito não é identificálos, nem mesmo individualizá-los.

Em alguns momentos faremos referência a discursos argumentativos dos profissionais representados sem, entretanto, utilizarmos suas falas e nem informações que possam identificá-los. Os discursos aqui coletivizados expressam o entendimento das autoras quanto às justificativas dos denunciados e não as palavras por eles proferidas. Tal percurso pode empobrecer um pouco o diálogo com os interlocutores, mas sem dúvida não produzirmos questionamentos seria muito pior. Por isso, fizemos desvios, dobras e reafirmamos nosso compromisso com a categoria bem como continuamos nosso intuito de colocar em análise alguns argumentos, lógicas e premissas que atravessam os discursos desses profissionais num momento em que sua atuação/intervenção é questionada, como já mencionado no início do texto.

Após leitura sistemática e comprometida das representações, foram construídas categorias de análise, aqui denominadas analisadores. Estes não foram, portanto, estabelecidos a priori, mas sim emergiram do nosso encontro com os textos produzidos por estes profissionais questionados em suas práticas.

Ao tomarmos um discurso como objeto de análise, o recortamos, circunscrevendo-o numa dada situação. Isso significa dizer que a nossa análise é apenas uma dentre múltiplas possibilidades, pois não esgotamos o objetivo em uma descrição/interpretação. Questões diferentes, postas por diversos analistas, conduzem a resultados distintos para um suposto mesmo objeto. Ou seja, os analisadores e resultados encontrados refletem o Olho do Observador posto que a neutralidade não existe.

Nesse sentido, podemos dizer que não há um dispositivo de interpretação absoluto, dado a priori. Ao contrário, este, assim como o discurso, constrói-se, particulariza-se na e a partir da relação, da questão que ele coloca diante dos dados coletados, que constituirão seu corpus e os quais ele visa compreender sob a luz do percurso teórico traçado.

Enfim, pretendemos com esse artigo dar visibilidade a algumas relações de saber-poder, conceitos e premissas que sustentam 0 
cotidiano desses psicólogos, especificamente, quando autorizados a falarem de suas práticas profissionais.

\section{Os analisadores}

Do encontro com os discursos dos psicólogos, alguns analisadores emergiram, no entanto, apenas três serão aqui problematizados. São eles: "A melhor defesa é o ataque": Desqualificando o Outro; Testemunha da conduta $x$ testemunha de caráter; A construção de uma prática psicológica legítima, ancorada no discurso científico.

\subsection{A melhor defesa é o ataque: desqualificando o Outro}

Em muitos processos analisados o denunciado parece colocar-se indisponível para problematizar e analisar suas práticas cotidianas, preferindo lançar mão de lógicas do senso comum como "a melhor defesa é o ataque". Pudemos perceber que nessa linha de pensamento, dentre o conjunto de estratégias identificadas nos discursos dos psicólogos, envolve a desqualificação dos denunciantes, ou seja, o denunciado vai produzindo a doença do/no denunciante na tentativa de desqualificação de seu comportamento, de sua fala. A preocupação desses profissionais centra-se na tentativa de produzir em seus textos (esclarecimentos e/ou defesa), a incoerência, a insanidade psicológica do denunciante e desse modo, por efeito, desconsiderar a denúncia na medida em que essa é produto de um Outro psicologicamente inconsistente.

Em outras palavras, visando sensibilizar e convencer a comissão de instrução o ato de desqualificar o denunciante acompanha, via de regra, uma estratégia de qualificá-lo em alguma patologia. Um dos recursos utilizados é o enquadramento de genitores na condição de negligente e mesmo de incapaz no cuidado de seus filhos. Observamos também a afirmação da vulnerabilidade psíquica pelo uso de medicação controlada como modo de invalidar a denúncia. Características ou dimensões de personalidade como psicopatia, egocentrismo, dentre outras também ganham visibilidade nos discursos dos profissionais questionados como estratégias de minimização da questão.

A título de ilustração, seguem os argumentos desqualificantes do denunciado, aqui apresentado com as palavras das autoras:

Ela é uma pessoa interesseira, seu objetivo é o de conseguir alguma outra vantagem. / Ele é egocêntrico, sempre quer se dar bem. I Ela, a genitora nunca cuidou devidamente dos filhos. / Trata-se de uma mãe negligente que não se 
responsabiliza pela família. /A mãe negligenciava as suas funções maternas. / Ele faz uso de medicação controlada.

Essa maneira que o psicólogo denunciado tem de encarar e instruir uma representação, seja em seus esclarecimentos ou defesa, nos remete aos estudos de Foucault, tanto com relação à noção de discurso como prática social bem como com relação à normalização enquanto estratégia de poder. (Foucault, 2006).

Outra estratégia de controle refere-se ao discurso da normalização, no qual se legitima a normalidade e, por extensão, assiste-se a emergência da anormalidade. Produz-se desse modo, o binômio inclusão/exclusão. Esses, não como antagônicos, mas como parte de uma mesma natureza de poder.

Esse processo de normalização que se fortaleceu nos últimos séculos teve o intuito de enquadrar e disciplinar. A norma não visava excluir ou rejeitar o sujeito, mas, pelo exame minucioso, incluí-lo ou não na ordem da anormalidade. Em outras palavras, ao incluir na anormalidade, na patologia, na negligência, exclui-se da normalidade, da sanidade, da responsabilidade.

O denunciado com seu discurso dito especialista inclui o denunciante na patologia, na anormalidade e assim o exclui como capaz, competente para fundamentar a denúncia. Podemos pensar ainda com Foucault (2006) a inclusão como fonte de dominação, de controle.

Essa postura de defesa pelo ataque ao invés de colocar em análise suas práticas, seu compromisso ético-político, busca minimizar ou neutralizar a responsabilidade do denunciado frente ao fato/situação geradora da denúncia. $E$, em última instância perde em potência de transformação, pois não gera mudança de posturas, nem análise de implicações na medida em que o inusitado não está consigo, mas no Outro.

\subsection{Testemunha da conduta $x$ testemunha de caráter}

Faz parte de uma das etapas processuais a facultativa apresentação de provas e testemunhas que poderão auxiliar na elucidação dos casos que geraram os processos éticos. Assim sendo, convém analisarmos a problemática que margeia a possibilidade de apresentação de provas documentais e testemunhais. Isso porque a psicologia é uma prática profissional que está atenta aos elementos subjetivos e abstratos da condição humana. Quais seriam então documentos e testemunhas que comprovam nosso modo de atuar profissionalmente?

Em processos analisados, as indicações de testemunhas dos psicólogos denunciados aludem a pessoas que mais do que auxiliar a compreensão do caso em tela, são acessadas para servirem como 
testemunhas de caráter destes profissionais. Outros processos também apresentam tal argumentação "generalizando sua conduta". O denunciado convoca pacientes ou ex-pacientes a falar de sua conduta profissional. Faz uso do lugar de saber-poder que ocupa na relação terapêutica solicitando uma avaliação positiva de sua conduta profissional. Nesse sentido, solicita, aos pacientes e familiares destes ou às instituições em que atuou profissionalmente, depoimentos que ressaltem de forma positiva essa conduta, enfocando sua ética ilibada e qualificação profissional.

Maingueneau (1997) tomando assertivas de Kerbrat-Orecchioni propõe que esconder-se atrás do discurso do outro seria uma forma eficiente de afirmar o próprio pensamento sem necessariamente assumir a responsabilidade deste. Indica que "Aí reside toda a ambiguidade do distanciamento: o locutor citado aparece, ao mesmo tempo, como o não-eu, em relação ao qual o locutor se delimita, e como a "autoridade" que protege a asserção (p.86).

Dessa forma, podemos afirmar que é justamente o afastamento entre o locutor e enunciado que ratifica e valoriza o pensamento, dando ao locutor ares de autoridade. Esse distanciamento provoca uma legitimação através do Outro. Na verdade, não é o Eu quem afirma sobre atitudes corretas, mas o exterior ao Eu, o que reforça a isenção do depoimento e sua veracidade. Tomando em conta que se trata de textos escritos, essa legitimação se intensifica de modo incontestável.

\subsection{A construção de uma prática psicológica legítima ancorada no discurso científico}

Podemos observar que, ao se posicionarem, alguns psicólogos lançam mão de discursos legitimados socialmente para reforçar seus argumentos. Percebemos que há uma compreensão por parte dos profissionais de que, por conta da própria positividade do trabalho da psicologia, seu aspecto essencialmente subjetivo, há a necessidade num momento objetivo (etapa processual), que outros discursos sejam alçados para dar corpo e autenticidade àquilo que está sendo dito.

Percebemos que alguns psicólogos utilizam o discurso jurídico, mas também o discurso científico como cenário para a construção das argumentações nos processos ético-profissionais. Nesse tópico, focaremos nesse último e nos efeitos gerados por ele.

Num dos processos, onde a qualidade e fundamentação técnicocientífica dos documentos produzidos são problematizadas, os psicólogos rebatem as críticas sustentando que sua produção está embasada em ampla referência bibliográfica. Além disso, ao falarem de suas práticas (número de entrevistas realizadas e conclusões constantes no documento), os psicólogos reiteram seu posicionamento ético por terem seguido textos e indicadores de 
pesquisas científicas reconhecidas. A título de ilustração, seguem argumentos de profissionais denunciados, aqui apresentados com as palavras das autoras: "Os documentos foram escritos embasados em dezenas de referências bibliográficas já citadas. / Minha prática estava embasada em pesquisas, indicadores e textos da área da psicologia. / Como meu documento não tem qualidade se foi embasado na literatura científica?".

O posicionamento dos psicólogos acima mencionados sugere duas máximas: a primeira, que a palavra do psicólogo em si não possui a força suficiente para defender a retidão de sua prática; a segunda, que o discurso científico é inquestionável e que a observância literal de suas prerrogativas implica em ações éticas.

Convém analisarmos estas máximas mais de perto. Em primeiro lugar, o esvaziamento do discurso do psicólogo, considerado insuficiente para chancelar uma prática, abre para pensarmos se a fala do profissional da psicologia só ganha autenticidade quando endossada por outros discursos. Nesse caso, o próprio funcionamento das Comissões de Ética em geral poderia seguir este caminho, isso se atuarem apenas no sentido da fiscalização (provocando assim a lógica de defesa compulsória) e não atuarem em seu viés de orientação, espaço onde as práticas poderiam ser mais profundamente refletidas, sem a resistência provocada pelas sanções.

Entretanto, se a psicologia é uma ciência, qual seria o problema de um psicólogo utilizar-se de arcabouço teórico dessa ciência para dar sentido e forma à sua prática e, neste caso, à suas defesas frente ao seu conselho profissional? A princípio, utilizar-se ou não do discurso científico não seria de modo algum um problema. Entretanto, o modo como o discurso científico atua nos discursos dos psicólogos denunciados é que nos chama a atenção.

Quando a ciência é convocada para sustentar uma prática, parece que os profissionais denunciados pouco se preocupam em elucidar os fatos ocorridos ou mesmo produzir uma reflexão mais aprofundada sobre seu fazer. Assim, o que percebemos é que o psicólogo se distancia do diálogo e terceiriza sua postura ética quando se esconde por trás dos dados científicos. O que nos parece é que uma prática, única e simplesmente por ter se baseado em pesquisas, torna-se necessariamente livre de questionamentos. Assim, percebemos que o que atua nos posicionamentos destes profissionais é uma ética transcendente (que se encontra nos livros e na ciência) e não uma ética imanente (que se encontra entre os indivíduos na vida prática).

Neste sentido, cabe pensarmos se o lugar da ciência, esse espaço da "verdade absoluta", também não deve ser questionado. Se como vimos em Foucault (2011), a própria psicologia passou por revisões ao longo da história, não deveríamos também rever seu lugar arbitrário frente às práticas profissionais, que mais do referendar, gera também práticas desengajadas? 


\section{Considerações finais}

Neste texto buscamos analisar os discursos de psicólogos denunciados dirigidos à Comissão de Orientação e Ética do CRP/RJ, discursos esses que buscam esclarecer suas práticas de trabalho no contexto de um processo ético-profissional. A partir das análises efetuadas, foi possível observar que havia um movimento por parte dos profissionais em legitimar suas práticas, deslegitimando aqueles que os denunciavam. Assim, ao invés de haver um investimento na explicitação de seu modo de trabalhar, os psicólogos denunciados se debruçavam na tarefa de apresentar as possíveis falhas de quem denuncia, invalidando seus discursos de denúncia.

Movimento análogo aparece ainda quando alguns profissionais buscam testemunhas de caráter para dar legitimidade àquilo que fazem, sejam familiares e/ou pacientes/usuários de seu serviço. Assim, de modo descontextualizado, pessoas são convidadas a falarem de uma situação de forma indireta, aferindo uma possível postura ética a partir do que conhecem do profissional em contextos outros. Ainda nesse sentido, pudemos observar que alguns profissionais se defendem ao ampararem suas práticas em documentos científicos. A prática do profissional fica impermeável a qualquer reflexão, tanto no que diz respeito ao ataque à figura do denunciante, quanto na utilização de testemunhas de caráter ou por meio de citação de referências científicas que indicariam precisão ética.

Nesse tipo de postura, parece haver uma necessidade de explicar/traduzir o universo do Outro (denunciante, testemunha ou textos científicos) e não apenas, como inicialmente solicitado, repensar sua prática e os efeitos por ela produzidos. Em outras palavras, o psicólogo denunciado cria uma distância que dificulta a possibilidade de haver uma análise de implicação, capaz de encaminhar outros modos de agir.

O conceito de implicação aqui apresentado nos foi fornecido por Lourau (2004) e se refere à análise das diferentes forças presentes em qualquer prática que, de um modo geral, produz ações que engendram, controlam, avaliam, rotulam, validam e invalidam em nome da ciência.

Entretanto, para podermos analisar com mais profundidade a questão, vale nos indagarmos sobre o que estaria também ensejando a postura desses profissionais, a partir de alguns questionamentos: os procedimentos processuais possibilitam a produção de reflexão por parte dos psicólogos? O posicionamento desses profissionais não seria também efeito da lógica de funcionamento das comissões de ética? 
Sem dirimir a responsabilidade dos profissionais aqui analisados e sem perder de vista de que há uma postura pouco comprometida que se apresenta nos discursos. Há, ainda, um contraponto que diz respeito aos sinais concretos que as comissões de ética emitem quando da instrução processual. Todo o formato de trabalho das comissões, que se pautam em documentos disciplinadores e suas indicações procedimentais, possuem uma linguagem e um funcionamento bastante próximos ao enquadre jurídico. Assim, mesmo que indiretamente, a aura da "defesa a todo custo" parece se fazer presente.

Por outro lado, como poderia a experiência subjetiva, que é a própria matéria de trabalho do psicólogo, ser defendida, testemunhada? As práticas psicológicas são situadas em contextos relacionais. Nesse sentido, onde mais poderia se amparar a legitimidade de uma prática que não na citação de conhecidos ou mesmo em livros e pesquisas? A palavra do psicólogo bastaria para sua própria defesa? Haveria outras formas de interação com os profissionais, onde suas práticas pudessem efetivamente ser debatidas, de modo que o discurso do Outro não fosse mais protagonista, mas sim coadjuvante?

Interessante observar que, não raro, alguns psicólogos, ao se defenderem, atacam não apenas o denunciante, mas também o próprio Conselho de Psicologia, considerando a instituição como algoz da situação. Não estaria aí algo sendo sinalizado?

É importante ainda observar que os conselhos de ética estão inseridos em um contexto mais amplo, que é a nossa própria sociedade. Assim, cumpre pensarmos no lugar ocupado pela ética mais amplamente. A criação de instituições que regulam a ética (sejam comissões de ética dos conselhos profissionais ou mesmo comitês de ética para pesquisas científicas), talvez aponte para um enfraquecimento da ética. A terceirização e institucionalização da ética parecem indicar que ela mesma não consegue se impor por força própria (Silveira e Huning, 2010). Essa fragilidade produz um efeito onde alguns indivíduos e instituições, em detrimento de outros, passam a ser eleitos para administrar e controlar a ética, tendo como mote a proteção da sociedade.

Importante observarmos se esse modo de lidar com a ética não estaria gerando indivíduos desengajados e com pouca reflexão sobre a sua ética singular e concreta do dia-a-dia. Isso porque já haveria pessoas e documentos que formalizariam o que é ou não é ser ético, assim, bastaria se estar atento à regulamentação. Nesse formato, os documentos deixam de ser orientadores para serem definidores de procedimentos, produzindo profissionais com conforto moral, mas não necessariamente com atitudes éticas.

A questão do lugar da ética em nossa sociedade não é simples. Mas talvez os comitês de ética possam trilhar um caminho onde haja cada vez mais investimento em um procedimento paralelo à 
disciplinarização: a orientação dos profissionais. Ampliar os espaços de discussão junto à categoria de modo a tentar entender seus principais desafios e entraves, e possibilitar que a ética seja refletida como algo em permanente construção, talvez sejam caminhos que reforcem espaços de diálogo, espaços esses que prescindam do ataque ou da defesa como únicos modos de contato com a ética.

\section{Referências}

Amorim M. (2001). O pesquisador e seu outro: Bakhtin nas Ciências Humanas. São Paulo: Musa Editora.

J. C. Anscombre, \& O. Ducrot (1998). L'Argumentacion dans la Langue. Liège. Bruxelles: Pierre Mardaga.

Bakthin, M. (1986). Marxismo e Filosofia da Linguagem, São Paulo: Hucitec.

Charaudeau, P. (1996). Para uma Nova Análise do Discurso. In: Carneiro, A. D. (Org.). Discurso da Mídia. (pp. 05-43), Rio de Janeiro: Oficina do Autor.

Foucault, M. (2000). A Ordem do Discurso. São Paulo: Edições Loyola.

Foucault, M. (2006). Poder e Saber. In: Foucault, M. Estratégia, poder-saber. Rio de Janeiro: Forense Universitária.

Foucault, M. (2011). Michel Foucault. Problematização do sujeito: Psicologia, Psiquiatria e Psicanálise. Rio de Janeiro: Forense Universitária, 2011.

Lourau, R. (2004). Implicação um novo paradigma? In Altoé, S. (Org). René Lourau: Analista Institucional em tempo integral, (pp. 246-258), São Paulo: HUCITEC.

Maingueneau, D. (1997). Novas Tendências em Análise do Discurso. São Paulo: Pontes.

Silveira, R. A. T. da., Huning, S. M.(2010). A tutela moral dos Comitês de Ética. Psicologia e Sociedade, 22(2), 388-395.

\section{Endereço para correspondência}

Lygia Santa Maria Ayres

Universidade Federal Fluminense

Departamento de Psicologia - Serviço de Psicologia Aplicada - SPA/UFF

Campus do Gragoatá, Bloco O, 5 andar, CEP 24210-201, Niterói - RJ, Brasil

Endereço eletrônico: lygia.ayres@gmail.com

\section{Cíntia de Sousa Carvalho}

Centro Universitário de Barra Mansa

Departamento de Direito

R. Ver. Pinho de Carvalho, 267, Centro, CEP 27330-550, Barra Mansa - RJ, Brasil

Endereço eletrônico: cintiapsicologia_51@hotmail.com

\section{Mariana Chaves Botelho Barreira}

Consultório particular 
Avenida Nossa Senhora de Copacabana, 435/414, Copacabana, CEP 22050-002, Rio de Janeiro - RJ, Brasil

Endereço eletrônico: maricfb@globo.com

Recebido em: 06/08/2014

Reformulado em: 01/08/2015

Aceito para publicação em: 06/08/2015

\section{Notas}

* Psicóloga, Doutora em Psicologia Social pela UERJ, pesquisadora da Universidade Federal Fluminense/UFF.

** Psicóloga, doutora em Psicologia Clínica pela PUC-Rio.

*** Psicóloga. 